\title{
Mathematical Modeling of Acid Deposition Due to Radiation Fog
}

\author{
SPyros N. Pandis and John H. Seinfeld \\ Department of Chemical Engineering and Environmental Quality Laboratory, \\ California Institute of Technology, Pasadena
}

\begin{abstract}
A Lagrangian model has been developed to study acidic deposition due to radiation fog. The model couples submodels describing the development and dissipation of radiation fog, the gas-phase chemistry and transfer, and the aqueous-phase chemistry. The model is applied to a radiation fog episode in Bakersfield in the San Joaquin Valley of California over the period January 4-5, 1985. Model predictions for temperature profile, fog development, liquid water content, gas-phase concentrations of $\mathrm{SO}_{2}, \mathrm{HNO}_{3}$, and $\mathrm{NH}_{3}, p \mathrm{H}$, aqueous-phase concentrations of $\mathrm{SO}_{4}^{2-}, \mathrm{NH}_{4}^{+}$, and $\mathrm{NO}_{3}^{-}$, and finally deposition rates of the above ions are compared with the observed values. The deposition rates of the major ions are predicted to increase significantly during the fog episode, the most notable being the increase of sulfate deposition. Pathways for sulfate production that are of secondary importance in a cloud environment may become significant in a fog. Expressing the mean droplet settling velocity as a function of liquid water content is found to be quite influential in the model's predictions.
\end{abstract}

\section{INTRODUCTION}

The importance of acid fog as a component of the general acidic deposition phenomenon has recently been recognized. For example, Hoffmann and coworkers [Waldman et al., 1982; Munger et al., 1983; Jacob et al., 1985] have reported $p \mathrm{H}$ values of fogs in southern California as low as 1.69 . These fogs were much more acidic, and concentrations of anions and cations such as $\mathrm{SO}_{4}^{2-}, \mathrm{NO}_{3}^{-}$, and $\mathrm{NH}_{4}^{+}$were higher by $1-2$ orders of magnitude than in precipitation in the same areas. Field measurements have provided valuable information concerning the chemical composition of acid fog, but the physicochemical processes leading to this composition have yet to be elucidated.

Mathematical models describing atmospheric processes are a major tool in our effort first to understand and then to control acidic deposition. The first step in acidic deposition processes is the emission to the atmosphere of $\mathrm{SO}_{2}$ and $\mathrm{NO}_{x} \cdot \mathrm{SO}_{2}$ and $\mathrm{NO}_{x}$ can be oxidized in the atmosphere, yielding sulfuric and nitric acid vapors. Due to its very low vapor pressure, sulfuric acid is rapidly incorporated into aerosol particles, while nitric acid may be scavenged by particles or droplets or remain in the gas phase. Inside a cloud or a fog, gas-phase species like $\mathrm{SO}_{2}, \mathrm{HNO}_{3}, \mathrm{NH}_{3}$, $\mathrm{H}_{2} \mathrm{O}_{2}$, and aerosol particles are scavenged by water droplets, resulting in a solution that can be significantly acidic. It was initially believed that the scavenging of these acids by cloud, fog, and rain droplets was the major source of sulfuric and nitric acid observed in precipitation. It is now recognized that cloudwater and fogwater acidity may result not only from incorporation of strong acids present in clear air but also from aqueous-phase oxidation reactions, most notably oxidation of S(IV) to S(VI). Several analyses of aqueous-phase atmospheric chemistry have been performed using mechanisms of varying complexity [Graedel and Goldberg, 1983; Jacob and Hoffmann, 1983; Chameides, 1984; Seigneur and Saxena, 1984; Schwartz, 1984; Jacob, 1986; Pandis and Seinfeld, 1989]. These studies are based on reaction mechanisms of the aqueous-phase chemistry in clouds or fog with or without gas-phase reactions, but with

Copyright 1989 by the American Geophysical Union.

Paper number 89JD01227.

0148-0227/89/89JD-01227\$05.00 no treatment of cloud or fog dynamics. The importance of parameters such as amount of liquid water, droplet lifetime, and amount of polluted air mixed in the cloud system to the chemical composition of the aqueous phase has been stressed in these studies.

Tremblay and Leighton $[1984,1986]$ developed a model of cloud dynamics with a simple treatment of cloud chemistry. Their initial one-dimensional model (1984) was later extended to a three-dimensional model (1986). Walcek and Taylor [1986] used a one-dimensional steady state cumulus cloud model with detailed aqueous but no gas-phase chemistry to study vertical distribution of acidity and sulfate production. Seigneur and Saxena [1988] presented a model with a simple treatment of cloud physics (updraft and precipitation) and detailed cloud chemistry and investigated sulfate formation in stratus and cumulus clouds. Several attempts have been made to model the life cycle of radiation fog with no treatment of atmospheric chemistry [Fisher and Caplan, 1963; Zdunkowski and Nielsen, 1969; Lala et al., 1975; Brown and Roach, 1976; Brown, 1980; Forkel et al., 1984, 1987; Turton and Brown, 1987].

Each of the above studies has focused either on the chemical processes associated with the gas and aqueous phase or the physics of clouds and fog. This study combines, for the first time, a detailed description of gas- and aqueousphase atmospheric chemistry with a basic treatment of radiation fog dynamics. The inclusion of the fog dynamics enables us to study the wet deposition of pollutants during fog episodes, the vertical variability of acidity and pollutant concentrations in a fog, and the changes of concentration of aqueous and gaseous species during the various stages of fog development.

A Lagrangian trajectory model has been used in this study for the description of radiation fog development and gas- and aqueous-phase chemistry. A trajectory model that follows a parcel of air as it traverses the airshed has been found to be a valuable tool for simulation of the chemical and physical processes occurring in a particular location. Even if such a model is not ideally suited for the prediction of concentration changes over extended spatial and temporal scales where an Eulerian description is preferable, the small computing cost of a trajectory model compared with a Eulerian grid model 
makes it ideal for the testing of chemical reaction mechanisms and model assumptions and for studying the sensitivity of the model to various inputs and parameters. Furthermore, the relatively low computing cost allows the use of higher vertical resolution than in a three-dimensional model and thus affords the opportunity to explore phenomena sensitive to height above the ground.

In this paper, we begin with a physical description of the system of interest, with emphasis on the physics of radiation fog. Next we present separately the gas-phase chemistry, aqueous-phase chemistry, and radiation fog dynamics submodels and then describe the complete model. The full model is then evaluated against data obtained during a well-documented radiation fog episode in the San Joaquin Valley of California [Waldman, 1986; Jacob et al., 1987]. Sensitivity studies address the effects of fog formation on the deposition rates and on the aerosol mass and the chemical pathways that contribute to sulfate formation.

\section{Radiation Fog and Acid Deposition}

By definition, a fog is a cloud of liquid water droplets near the Earth's surface that reduces visibility to less than $1 \mathrm{~km}$ [Eagleman, 1985]. If humid air near the ground is cooled sufficiently, it becomes saturated, and a fog develops. Typical fogs are classified according to the process that causes the cooling of the air. The types identified are upslope, advection, frontal, and radiation fogs [Eagleman, 1985]. Upslope fog is generated by the cooling of the air as it is forced to rise over hills and mountains. Advection fog is created through contact cooling of warm air with a cold surface or through advection of cold air over warm water. Frontal fog can be created as weather, especially warm fronts, passes through an area. Finally, radiation fog (or ground fog) is generated as the Earth's surface cools by loss of radiation to space at night.

This study focuses on the development of radiation fog because it is one of the most frequently encountered fog forms in heavily polluted areas [Munger et al., 1989]. It is important to note, however, that the main ideas concerning the modeling of radiation fog can be extended and applied to other fog categories and especially to advection and upslope fog.

The various stages in the development of a typical radiation fog can be visualized by following the movement of an air parcel during a 24-hour period. During the daytime the air parcel collects water vapor and aerosol particles (sea salt, dust, primary and secondary particles of anthropogenic origin). The air temperature is high, and the relative humidity is low. In the late afternoon the heat loss of the ground due to radiation to space exceeds the heating rate due to solar radiation, and the ground temperature starts decreasing. After sunset, as the cooling of the ground continues, the air within the lowest few meters also cools, due to heat transfer to the cooler ground. The radiational heat loss of the surface is partially balanced by heat conducted upward to the ground surface because of the temperature gradient created in the first few centimeters in the soil. At a specific relative humidity, which for most soluble components in the atmosphere is well below $100 \%$, aerosol particles that are not already liquid deliquesce into aqueous solution drops. As the ambient relative humidity keeps increasing, the droplets undergo a slow equilibrium growth by water vapor diffusion
[Pruppacher and Klett, 1980]. The air near the ground approaches saturation. At this stage, dew deposition occurs.

Whether fog forms at this point depends on several factors such as cloud cover (clouds reduce radiative cooling), wind speed (turbulent diffusion tends to dry and may warm the air), and water vapor concentration. If there are no clouds and the wind speed is very low and the water vapor concentration is high enough, then fog starts forming in the lowest few meters. When the relative humidity reaches a critical supersaturation, depending on the size and chemical composition of the aerosol present, the droplets become activated and grow freely by water vapor diffusion.

The air near the top of the fog is cooling rapidly due to radiation of the fog droplets to space, and consequently, the fog propagates upward. At the same time that the fog thickness increases, the radiative losses of the ground decrease due to the liquid water shield over it, and the ground temperature starts increasing from heat conduction upward through the soil. The air near the ground thus warms, and the fog near the ground thins out.

When the sun comes out, fog dissipation is accelerated, and liquid water evaporates rapidly at both the top and bottom of the fog. As the relative humidity decreases, the water evaporates from the fog droplets, leaving aerosol particles. The fog life cycle affects the aerosol concentration and composition in various ways. The aerosol particles grow because of water vapor diffusion, and their gravitational settling and subsequent deposition are accelerated. At the same time, fog droplets scavenge soluble gases like nitric acid and ammonia and act as the medium for various aqueous-phase reactions, including the oxıdation of absorbed $\mathrm{SO}_{2}$ to sulfate.

\section{Model. Description}

A complete model for acidic deposition due to fog should include descriptions of several physicochemical processes for all three phases existing in the atmosphere, namely, the gaseous, the aqueous, and the aerosol phase (Figure 1). Important processes that should be modeled are the emission of gas-phase species $\left(\mathrm{SO}_{2}, \mathrm{NH}_{3}, \mathrm{NO}\right.$, hydrocarbons) and particles, the reactions of species in the gas phase, the nucleation and condensation of gaseous species to aerosol particles, and the mass transfer (diffusion and advection) and dry deposition of gases and aerosol. Additionally, a description of the physical process that causes the cooling of the moist air (radiative cooling for radiation fog) is necessary. The condensation of water vapor on the aerosol particles that serve as condensation nuclei and the subsequent growth of the water droplets is the next step. After the appearance of the aqueous phase, one should account for the scavenging of gaseous species by the water droplets, their ionization, and aqueous phase reactions. The gravitational settling of droplets and their deposition on the ground must also be described. The last step of the phenomenon is the evaporation of the aqueous phase, leaving an aerosol residue.

A full description of all the above processes requires a model capable of predicting the changes of the aerosol and water droplet size chemical composition spectrum. The present study focuses on the chemical changes in both the gas and aqueous phases, and an explicit treatment of the aerosol microphysics has not been included. Size-dependent processes of interest such as the aerosol particle scavenging 


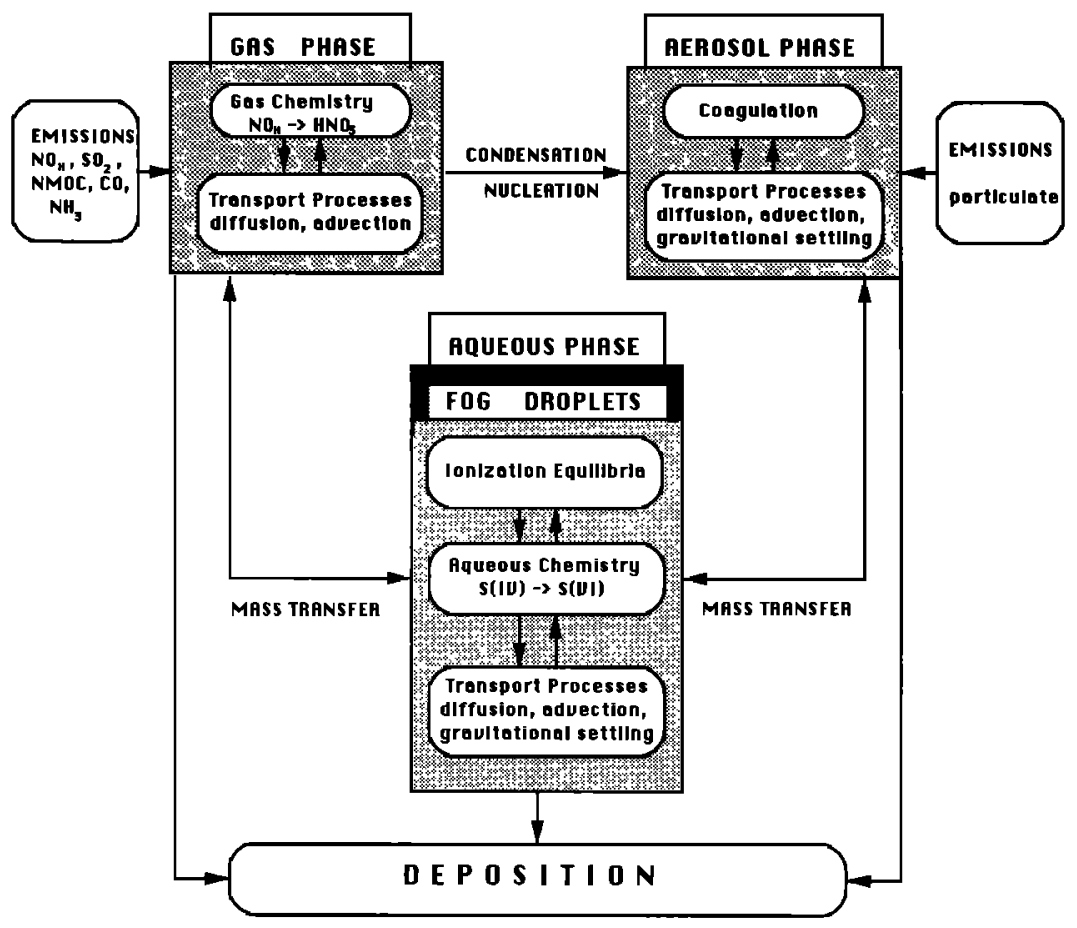

Fig. 1. Atmospheric processes leading to acid deposition.

by fogwater, gravitational settling, and radiative cooling of fog droplets have been parameterized. The model is capable of predicting the liquid water profile, and the gas- and aqueous-phase concentration profiles for all species but does not account for the size or composition spectrum of aerosol particles or fog droplets.

The mathematical model employed in this study consists of three interacting submodels simulating gas-phase chemistry, fog development, and aqueous-phase chemistry. These three models will initially be described independently.

\section{Gas-Phase Model}

The gas-phase model describes atmospheric chemical reactions, turbulent vertical diffusion, horizontal advective transport, and ground level pollutant deposition. It is based on the numerical solution of the Lagrangian trajectory form of the atmospheric diffusion equation presented by McRae et al. [1982]. Except for the changes mentioned below, the methods employed here are as described by McRae et al. [1982].

The detailed SAPRC/ERT gas-phase chemical reaction mechanism [Carter et al., 1986] with the modifications and extensions of Carter and Atkinson [1988] has replaced the previously used mechanism. It contains 154 reactions and 62 species (39 active, seven accumulating, and 16 steady state species). The photochemical mechanism preparation and emissions processing software of Carter and Atkinson [1988] has been used to prepare the gas-phase mechanism dependent part of the code.

\section{Radiation Fog Model}

The governing equations of the radiation model are the one-dimensional continuity equations for heat (for air and soil), water vapor, and liquid water:

$$
\begin{gathered}
\frac{\partial T}{\partial t}=-\frac{1}{\rho c_{p}} \frac{\partial F_{N}}{\partial z}+\frac{\partial}{\partial z}\left[K_{h}\left(\frac{\partial T}{\partial z}+\Gamma\right)\right]+\frac{L}{\rho c_{p}} C \\
\frac{\partial T_{s}}{\partial t}=K_{s} \frac{\partial^{2} T_{s}}{\partial z^{2}} \\
\frac{\partial q}{\partial t}=\frac{\partial}{\partial z}\left(K_{q} \frac{\partial q}{\partial z}\right)-C \\
\frac{\partial w}{\partial t}=\frac{\partial}{\partial z}\left(K_{w} \frac{\partial w}{\partial z}\right)+\frac{\partial G}{\partial z}+C
\end{gathered}
$$

where $T$ is the air temperature (in degrees Kelvin), $\rho$ the air density (in $\mathrm{g} \mathrm{m}^{-3}$ ), $c_{p}$ the specific heat of air (in J K ${ }^{-1} \mathrm{~g}^{-1}$ ), $F_{N}$ the net radiative flux (in $\mathrm{W} \mathrm{m}{ }^{-2}$ ), $K_{h}, K_{q}, K_{w}$ the exchange coefficients for heat, water vapor, and liquid water, respectively (in $\left.\mathrm{m}^{2} \mathrm{~s}^{-1}\right), \Gamma$ the adiabatic lapse rate $(\Gamma$ $=0.0098 \mathrm{~K} \mathrm{~m}^{-1}$ ), $L$ the latent heat of vaporization (in $\mathrm{J} / \mathrm{g}$ water), $C$ the condensation rate (in $g$ water $\mathrm{m}^{-3} \mathrm{~s}^{-1}$ ), $T_{s}$ the temperature in the soil (in $\mathrm{K}$ ), $K_{s}$ the soil thermal conductivity (in $\mathrm{m}^{2} \mathrm{~s}^{-1}$ ), $q$ the water vapor concentration (in $\mathrm{g}$ water $\mathrm{m}^{-3}$ ), $w$ the liquid water concentration (in $\mathrm{g}$ water $\mathrm{m}^{-3}$ ), and $G$ the gravitational flux of liquid water (in $\mathrm{g}$ water $\mathrm{m}^{-2} \mathrm{~s}^{-1}$ ).

The radiation flux $F_{N}$ is calculated using the radiation scheme of Zdunkowski et al. [1982] for the solar and infrared emission spectrum. This scheme incorporates the effects of atmospheric water vapor, carbon dioxide, ozone, nitrogen dioxide, aerosol particles, and multiple layers of clouds or fog. A total of 74 grid points extending from the ground surface to a height of $50 \mathrm{~km}$ have been found to provide sufficient accuracy for the solution of the equations for the radiative fluxes in this study.

The exchange coefficients for heat, water vapor, and liquid 
water are assumed equal in this model [Brown and Roach, 1976]. They are given by [Shir, 1973]

$$
K_{h, q, w}=\frac{K^{n}}{\phi_{h, q, w}(z / L)}
$$

where $K^{n}$ refers to neutral conditions and is given by

$$
\left.K^{n}=\frac{1}{2} k u_{* z} z \exp \left(\frac{-4 z}{H}\right)+\frac{1}{1+16(z / H)^{1.6}}\right]
$$

In the above formulas, $H=0.455 u_{*} / f$ scales the boundary layer height [Shir, 1973], $u_{*}$ is the friction velocity, $f$ the Coriolis parameter, $L$ the Monin-Obukhov length, and $\phi_{h, q, w}$ the appropriate Monin-Obukhov profile function. The simplifying assumption is made that $\phi_{h}=\phi_{q}=\phi_{w}$. The Monin-Obukhov profile functions used in this study are [Zdunkowski et al., 1976]

Unstable regime

$$
\phi_{h}\left(\frac{z}{L}\right)=0.76\left(1-16 \frac{z}{L}\right)^{-1 / 2} \quad \frac{z}{L}>-10
$$

The functions are evaluated at $z / L=-10$ if $z / L<-10$.

Stable regime

$$
\begin{gathered}
\phi_{h}\left(\frac{z}{L}\right)=0.74+9.62 \frac{z}{L}+29.6\left(\frac{z}{L}\right)^{2} \quad \frac{z}{L}<0.08 \\
\phi_{h}\left(\frac{z}{L}\right)=1.2+6.1 \frac{z}{L} \quad \frac{z}{L}>0.08
\end{gathered}
$$

The thermal conductivity of the soil, $K_{s}$, is assumed to remain constant for all depths during the simulation.

The gravitational flux of liquid water $G$ is defined in terms of a mean settling velocity $u_{\mathrm{av}}$ by

$$
G=w u_{\mathrm{av}}
$$

If the droplet size distribution, $n(r, z)$, and the settling velocity of droplets as a function of size, $u(r)$, are known, the mean settling velocity, $u_{\mathrm{av}}$, can be obtained from

$$
u_{\mathrm{av}}=\frac{\int_{0}^{\infty} n(r, z) u(r) r^{3} d r}{\int_{0}^{\infty} n(r, z) r^{3} d r}
$$

Because the fog droplet distribution at height $z$ is not calculated by this model, we have parameterized the mean settling velocity $u_{\mathrm{av}}$ following Brown and Roach [1976] and Forkel et al. [1984, 1987] as

$$
u_{\mathrm{av}}=a_{g} w
$$

Various measured fog droplet spectra [Waldman, 1986] have been used to calculate an average $a_{g}$ value of $0.120 \mathrm{~m}^{4} \mathrm{~g}^{-1}$ $\mathrm{s}^{-1}$. The terminal velocity of droplets in (10) has been calculated using Stoke's law.

To avoid an explicit treatment of the fog microphysics, we assume that inside the fog the water vapor pressure always attains its saturation value [Brown and Roach, 1976]. Various field measurements suggest that fogs generally have low supersaturations, with largest values during the initial stage of fog development. Therefore our assumption leads to a small loss of accuracy in the calculated liquid water values but at the same time reduces drastically the computing time requirements, as we do not have to solve the droplet growth equation [Brown, 1980]. The integration of (1), (3), and (4) is performed in two steps. First, the equations are integrated for one time step, neglecting the condensation/evaporation term $(C=0)$. This integration results in values of air temperature, water vapor, and liquid water concentrations, $T_{0}, q_{0}$, and $w_{0}$, respectively. In general, the water vapor concentration will be different from the saturation concentration, $q_{s o}$, at temperature $T_{0}$. If the air is supersaturated, some water vapor has to be condensed. If it is subsaturated, some of the existing liquid water is evaporated. Therefore the three variables are adjusted to $T^{\prime}, q^{\prime}, w^{\prime}$, where $q^{\prime}$ is the saturation concentration corresponding to $T^{\prime}$. The new values are calculated by solving the water mass balance, the energy balance, and the Clausius-Clapeyron equations simultaneously [McDonald, 1963].

\section{Boundary Conditions}

Equations (1), (3), and (4) are solved in the region extending from the ground surface to a height of $300 \mathrm{~m}$. This region has been chosen large enough to include the fog top in most radiation fog episodes. Equation (2) is solved from a depth of $1 \mathrm{~m}$ below the surface to the ground surface. The grid used is unequally spaced with 52 points above ground level for the solution of (1), (3), and (4), and 13 points inside the soil for the solution of (2). The grid is much denser near the ground surface. This grid selection was proven to provide both accuracy and speed for subsequent calculations.

The boundary conditions applied to the top $(z=300 \mathrm{~m})$ of the model region are

$$
\begin{gathered}
T=\text { const }=T_{\text {top }} \\
q=\text { const }=q_{\text {top }} \\
w=0
\end{gathered}
$$

and for the bottom level are

$$
T_{s}=\text { const }=T_{\text {bot }} \quad z=-1 \mathrm{~m}
$$

Finally, for the ground surface the liquid water concentration is assumed to be zero, $w=0$, and the air and soil temperature are considered to be the same, $T=T_{s}$. From the continuity of heat fluxes at the air-soil interface [Turton and Brown, 1987],

$$
-F_{N}+F_{H}+F_{L}-F_{S}=0 \quad z=0
$$

where $F_{N}$ is the net radiative flux (long-wave and shortwave) incident at the surface, $F_{H}$ and $F_{S}$ are the sensible heat fluxes reaching the interface through the air and the soil, and $F_{L}$ is the latent heat flux. The surface water vapor concentration $q_{1}$ is calculated by [Turton and Brown, 1987]

$$
q_{1}=f_{p} q_{\mathrm{sar}}\left(T_{1}\right)+\left(1-f_{p}\right) q_{2}
$$

where $q_{\mathrm{sat}}\left(T_{1}\right)$ is the saturation water vapor concentration of the ground surface which has temperature $T_{1}, q_{2}$ is the water vapor concentration for the first grid point above ground level, and $f_{p}$ is given by [Turton and Brown, 1987] 


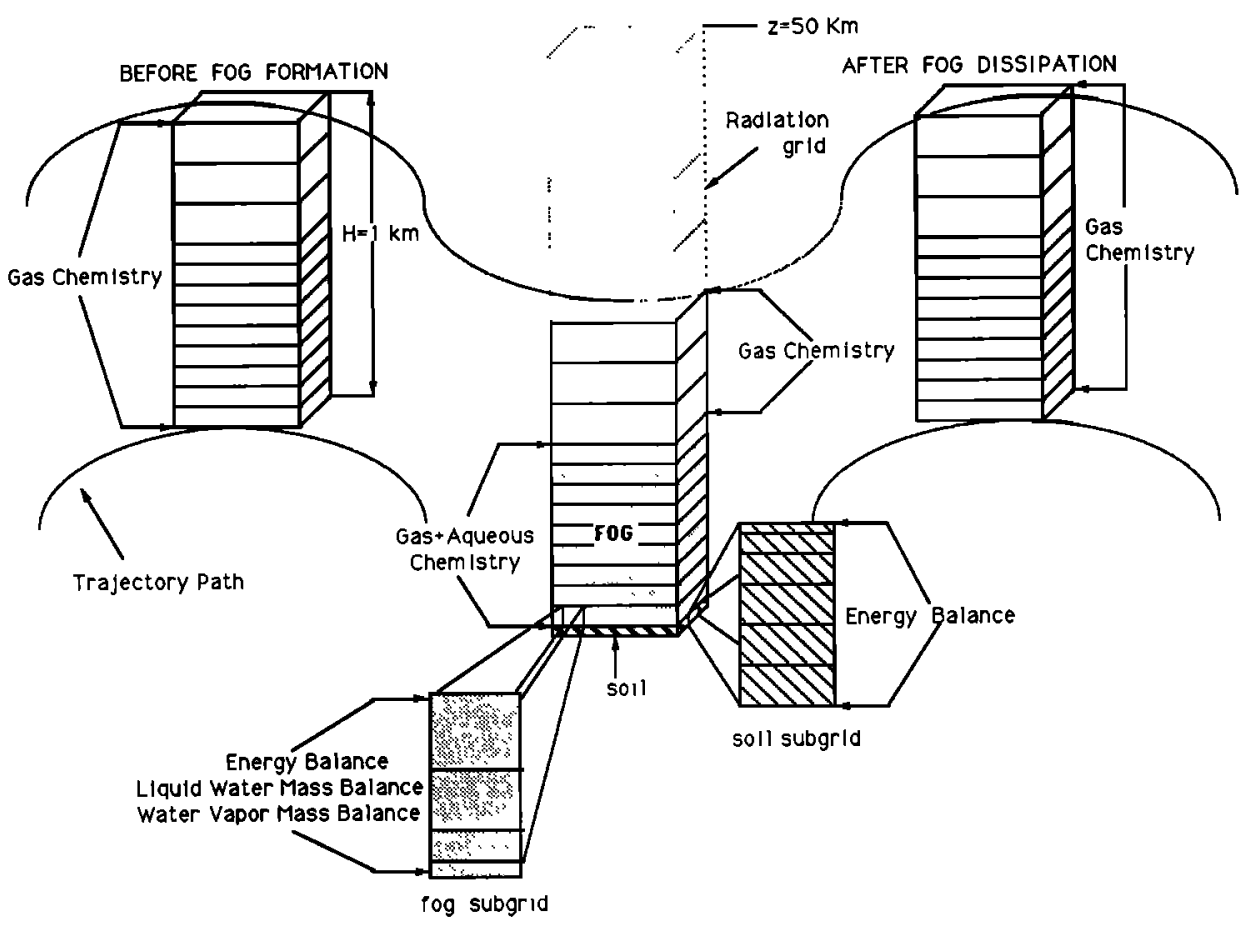

Fig. 2. Schematic representation of the vertically resolved Lagrangian trajectory model for radiation fog.

$$
f_{p}=\left(z_{2} / K_{h 1}\right) /\left(z_{2} / K_{h 1}+r_{s}\right)
$$

where $r_{s}$ is the surface resistance. A value of $60 \mathrm{~s} \mathrm{~m}^{-1}$ is used in this study following Turton and Brown, [1987]. For dew deposition that is $q_{\text {sat }}\left(T_{1}\right)<q_{2}, f_{p}$ is set equal to unity.

The system of the four partial differential equations is solved using the Crank-Nicolson method with a time step of $1 \mathrm{~s}$. No stability difficulties were encountered for this time step.

\section{Aqueous-Phase Model}

The aqueous-phase chemical reaction mechanism used in this study is described by Pandis and Seinfeld [1989]. The mechanism includes the dynamic exchange of species between the gaseous and aqueous phases in a homogeneous parcel of air containing liquid water droplets. The chemical mechanism includes 49 individual aqueous-phase species, 17 aqueous-phase ionic equilibria, 20 gas-phase aqueous-phase reversible reactions, and 109 aqueous-phase reactions.

\section{Full Model Description}

The full Lagrangian model describes the physicochemical processes occurring in a vertical column containing a prescribed number of computational grid cells $(12$, in the present computation). The region where the fog is expected to grow (the first 300 meters above the ground) is divided into nine cells, while the remaining three cells cover the height from 300 to $1000 \mathrm{~m}$. The size of each vertical cell remains constant during the simulation (Figure 2).

Each simulation is divided into three stages. In the first stage, before fog development, the model operates like an ordinary air quality trajectory model with only the gas-phase submodel active [McRae et al., 1982]. The variables calculated by the model in this stage are the gas-phase concentrations $c_{g i}$. Their change is calculated by

$$
c_{g}^{(t+\Delta t)}=A_{\text {gas }}(\Delta t) c_{g}^{(t)}
$$

where $A_{\text {gas }}$ is the gas-phase operator described for the gas-phase submodel.

At this stage the temperature and relative humidity constitute an input to the model. When the relative humidity exceeds $90 \%$, the first stage is over, and we enter the fog development stage. Initial temperature and relative humidity profiles are provided as an input, and the fog submodel becomes active. The first nine of the 12 major cells of the gas submodel are divided into smaller cells for the solution of the fog model equations (1), (3), and (4). When liquid water is created in a cell, the aqueous-phase chemistry submodel is also used. The existing aerosol particles are assumed to be completely scavenged by fog droplets upon the formation of a liquid water phase [Ten Brink et al., 1987]. In this way, the aerosol mass provides the initial concentrations of sulfate, nitrate, and ammonia in fogwater.

The aqueous-phase chemistry calculation is performed within the fog region of the main grid. The liquid water content for each of these cells is an average over the liquid water profile provided by the fog submodel.

During radiation fog, wind speeds remain generally under $2 \mathrm{~m} \mathrm{~s}^{-1}$ [Forkel et al., 1987; Waldman, 1986]; therefore during the life cycle of the radiation fog, one can assume that the Lagrangian cell is stationary. Under this assumption, the energy balance is valid because the cell remains more or less over the same piece of land throughout the simulation.

The full set of partial differential equations for the fog, gaseous, and aqueous phases is solved using an operator splitting technique, in order to decouple the fog growth, the gas-phase chemistry and vertical transport, and the aqueousphase chemistry. If $F_{i}$ is the variable vector containing the gas- and aqueous-phase concentrations and fog variables, its value at time $t+\Delta t$ is obtained from that at time $t$ by 


$$
F_{1}^{(t+\Delta t)}=A_{\mathrm{gas}}(\Delta t) A_{\mathrm{fog}}(\Delta t) A_{\mathrm{aq}}(2 \Delta t) A_{\mathrm{fog}}(\Delta t) A_{\mathrm{gas}}(\Delta t) F_{t}^{(t)}
$$

where $A_{\text {gas }}, A_{\text {aq }}$, and $A_{\text {fog }}$ are the gaseous-chemistry, aqueous-chemistry, and fog operators described above.

The second stage of simulation ends when the fog dissipates. At this point, when all the liquid water has been evaporated, the fog and aqueous chemistry operators become inactive, and the model becomes once more an ordinary gas-phase only model.

\section{Application of the Model}

The Lagrangian radiation fog model has been applied to simulate atmospheric conditions in the San Joaquin Valley of California (Bakersfield's Meadows Field Airport) from 1700 PST on January 4 to 1000 PST on January 5, 1985. The main goals of this simulation are to evaluate the model's performance against a well-documented episode to improve our understanding of the interaction of the various physical and chemical processes taking place during a radiation fog. About $10 \mathrm{CPU}$ hours on a micro-Vax III were required for the simulation.

During January 4 and 5, 1985, an extensive sampling network was operated in the San Joaquin Valley of California as a part of a 2-month study [Waldman, 1986; Jacob et al., 1987]. The gas-phase concentrations of $\mathrm{SO}_{2}, \mathrm{HNO}_{3}$, and $\mathrm{NH}_{3}$ were monitored. Aerosol samples were collected on open-faced Teflon filters, and fogwater samples were collected with a rotating arm collector. The fog liquid water content was determined from the collection rate of the rotating arm collector, assuming a collection efficiency of $60 \%$. The fogwater $p \mathrm{H}$ and the aqueous-phase concentrations of $\mathrm{S}(\mathrm{IV}), \mathrm{HCHO}, \mathrm{NH}_{4}^{+}, \mathrm{SO}_{4}^{-}, \mathrm{NO}_{3}^{-}, \mathrm{Cl}^{-}$, and trace metals ( $\mathrm{Fe}, \mathrm{Mn}, \mathrm{Na}, \mathrm{K}, \mathrm{Ca}, \mathrm{Mg}, \mathrm{Pb}$, and $\mathrm{Cu}$ ) were measured. The aerosol concentrations of $\mathrm{NH}_{4}^{+}, \mathrm{NO}_{3}^{-}, \mathrm{SO}_{4}^{2-}, \mathrm{Cl}^{-}$and several trace metals were determined. Additionally, the fog deposition rates for the major ions were monitored using polystyrene petri dishes and polyethylene buckets. Surface winds in the valley are determined at several sites, and vertical profiles of temperature, relative humidity, wind speed, and wind direction were recorded every $4-8$ hours using a tethersonde. An inert tracer was continuously released for 23 hours between 1800 PST on January 4 and 1700 PST on January 5, 1985, to monitor the fate of sulfur dioxide in the valley. The complete data sets have been reported by Waldman [1986] along with detailed descriptions of the sampling techniques used.

\section{Input Data for the Model}

All the field data used are from the work of Waldman [1986] and Jacob et al. [1987] for the Bakersfield site unless another source is mentioned. Measured vertical profiles for temperature are presented in Figure 4. The profiles of 1700 PST have been used as initial conditions for the fog model. The profiles predicted by the fog model are also presented in the same figure. Due to lack of any other information, the initial soil temperature has been chosen to vary according to $T_{s}=278.25-12.25 z$ for $-0.4 \mathrm{~m}<z \leq 0$ and $\left(T_{s}=283.15\right.$ K) for $-1 \mathrm{~m}<z \leq-0.4 \mathrm{~m}$, in agreement with Forkel et al. [1984]. Representative soil properties assumed here are $K_{s}=3.210^{-7} \mathrm{~m}^{2} \mathrm{~s}^{-1}, c_{s}=1255 \mathrm{~J} \mathrm{~kg} \mathrm{~K}^{-1}$, and $\rho_{s}=1600 \mathrm{~kg}$ $\mathrm{m}^{-3}$ [Zdunkowski and Nielsen, 1969]. The wind speeds at

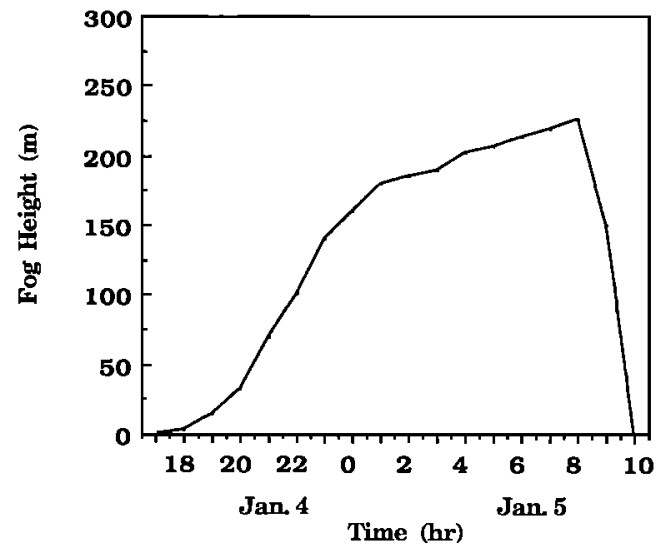

Fig. 3. Predicted top of the fog layer.

the $2.85-\mathrm{m}$ level during this night were lower than $2 \mathrm{~m} \mathrm{~s}^{-1}$. A constant value of $1.5 \mathrm{~m} \mathrm{~s}^{-1}$ has been assumed for the simulation.

The emissions are taken from the NAPAP 5.21980 emissions inventory [U.S. Environmental Protection Agency, 1986] for a winter weekday, with the exception of $\mathrm{SO}_{2}$ and $\mathrm{NH}_{3}$ emissions. The $\mathrm{SO}_{2}$ emission rate is assumed constant at $7.1 \times 10^{-10} \mathrm{~kg} \mathrm{~m}^{-2} \mathrm{~s}^{-1}$, obtained from a $1984 \mathrm{SO}_{2}$ inventory for the San Joaquin Valley [Aerovironment Inc., 1984]. $\mathrm{An} \mathrm{NH}_{3}$ emission rate of $3.4 \times 10^{-11} \mathrm{~kg} \mathrm{~m}^{-2} \mathrm{~s}^{-1}$ has been used for the San Joaquin Valley, based on the estimation of Jacob [1985].

Initial gas-phase concentrations of $\mathrm{SO}_{2}, \mathrm{NH}_{3}, \mathrm{HNO}_{3}$, and aerosol particle mass concentrations for $\mathrm{SO}_{4}^{2-}, \mathrm{NO}_{3}^{-}$, and $\mathrm{NH}_{4}^{+}$are based on the corresponding ground-level measurements. The remainder of the gas-phase concentrations are computed by an extra simulation using the gas-phase submodel from 0000 to 1700 PST on January 4. Due to lack of other information, an initial $\mathrm{H}_{2} \mathrm{O}_{2}$ vapor concentration of 2 $\mathrm{ppb}$ has been assumed based on the measurements of Heikes et al. [1987]. The aqueous-phase concentrations of $\mathrm{Fe}^{3+}$ and $\mathrm{Mn}^{2+}$ are assumed to be 225 and $33 \mu \mathrm{g} / \mathrm{L}$ water according to the observations of Waldman [1986] for this fog episode.

\section{Fog Development}

The radiation model predicts that radiation fog starts developing just after sunset (1700 PST), reaches a maximum height of about $230 \mathrm{~m}$, and dissipates by 1000 PST, the morning of the next day. The predicted fog evolution is shown in Figure 3. The predicted start and end of the radiation fog agree exactly with the observations of Waldman [1986]. The predicted fog height agrees with the relative humidity profiles measured by tethersonde. These profiles suggest that the first 210,240 , and $270 \mathrm{~m}$ of the atmosphere were saturated at 0030,0530 , and 0900 PST, respectively. The predicted and observed temperature profiles (Figure 4) are in close agreement.

The hourly averaged liquid water content predicted at ground level is compared with the measured values in Figure 5 . The maximum liquid water attained in the fog is predicted to be $0.28 \mathrm{~g} \mathrm{~m}^{-3}$, matching closely the $0.29 \mathrm{~g} \mathrm{~m}^{-3}$ reported. The model appears to have a tendency of slightly overpredicting the liquid water content of the fog.

The predicted hourly averaged liquid water deposition rates are presented in Figure 6. A maximum of $24.6 \mathrm{~g} \mathrm{~m}^{-2}$ 

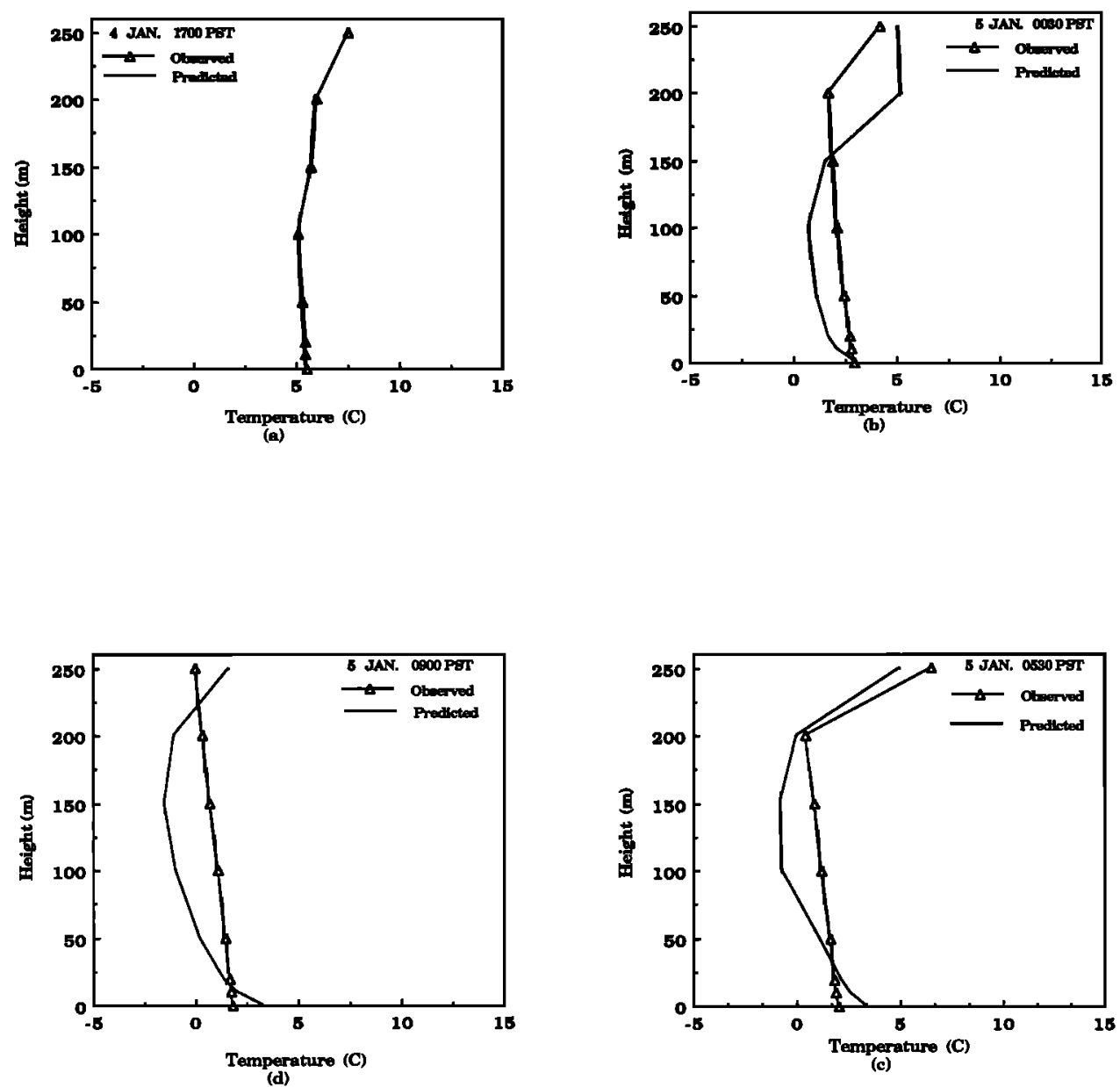

Fig. 4. Comparison of the vertical temperature profiles predicted by the model with the observations of Waldman [1986].

$\mathrm{h}^{-1}$ is attained around midnight. These liquid water rates are closely consistent with the deposition velocities of $1-3 \mathrm{~cm}$ $\mathrm{s}^{-1}$ reported by Waldman [1986].

The results indicate that the radiation fog submodel is very successful in describing the observed fog development and in predicting variables of interest like the liquid water

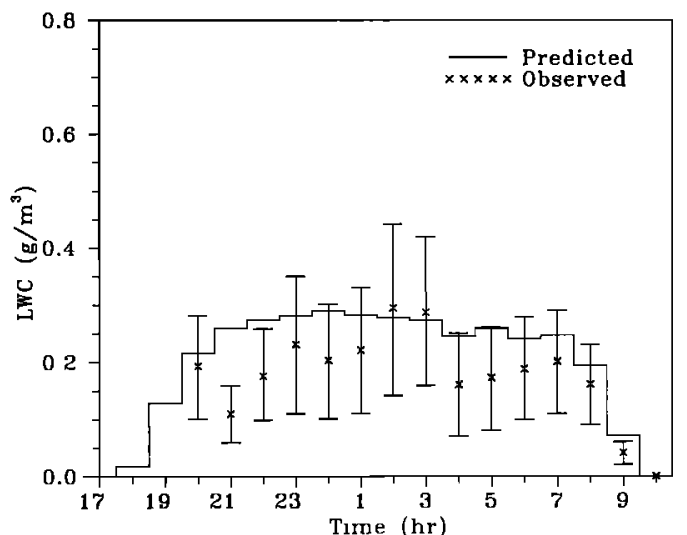

Fig. 5. Comparison of the predicted hourly averaged liquid water content for the ground-level grid cell with the observations of Waldman [1986]. The uncertainty in the measurements as reported by Waldman [1986] is indicated by the data ranges. content, the liquid water deposition rates, and the fog height.

Three representative calculated liquid water profiles are shown in Figure 7. An interesting feature is that after the initial fog development stage, after midnight in this simulation, the liquid water profile starting at a few meters high and ending near the fog top remains relatively flat.

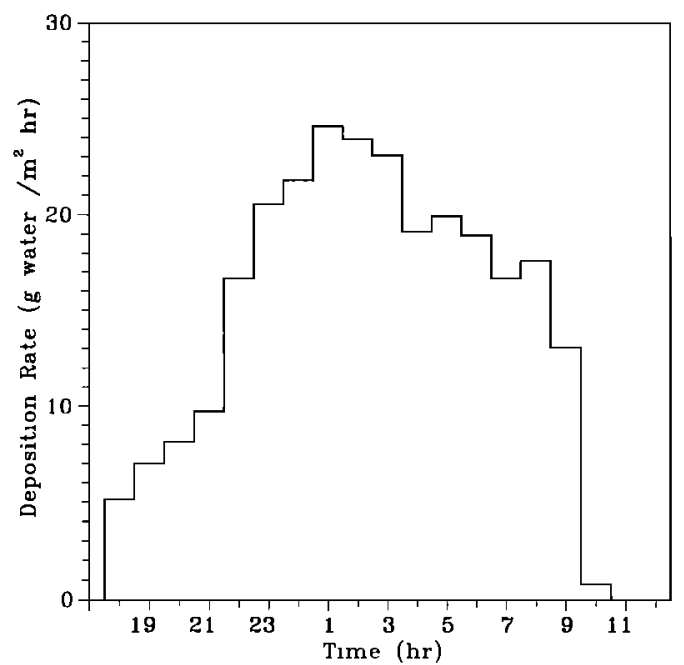

Fig. 6. Predicted hourly averaged liquid water deposition rates. 


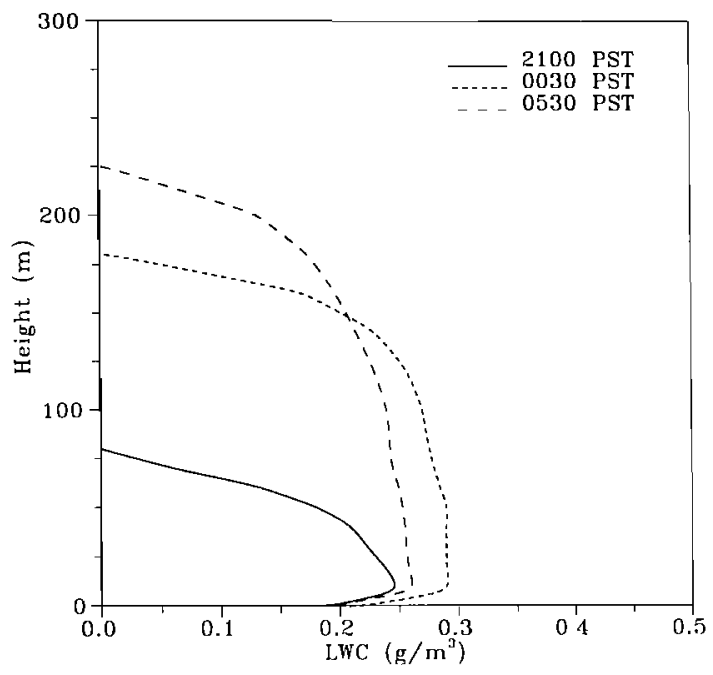

Fig. 7. Predicted vertical liquid water concentration profiles for 2100, 0030, and 0530 PST.

\section{Species Concentrations}

Predicted and observed hourly averaged values for the $p \mathrm{H}$ and the aqueous-phase concentrations of $\mathrm{NH}_{4}^{+}, \mathrm{SO}_{4}^{2-}$, and $\mathrm{NO}_{3}^{-}$are presented in Figure 8 .

The $p \mathrm{H}$ of the fog at ground level is initially around 7.0, gradually drops to 4.5 at 0700 PST as the fog is developing, and in the dissipation stage of the fog it drops further, reaching a value of 3.3 at $0900 \mathrm{PST}$. The $p \mathrm{H}$ prediction of the model is very good, with a small tendency to underestimate.

The major ionic species in fogwater are in this case $\mathrm{NH}_{4}^{+}$, $\mathrm{SO}_{4}^{2-}$, and $\mathrm{NO}_{3}^{-}$. The high $p \mathrm{H}$ during most of the fog is a result of the ammonia emissions in the area due to widespread agricultural and livestock activities. The maximum predicted concentration of $\mathrm{NH}_{3}, 2000 \mu \mathrm{eq} / \mathrm{L}$, as well as the rest of the predicted values, are in close agreement with the reported values.

The $\mathrm{SO}_{4}^{2-}$ is the anion that closely balances $\mathrm{NH}_{4}^{+}$. The hourly averaged sulfate concentrations do match closely the observed concentrations, with a tendency of the model to overpredict the sulfate concentrations. The reasons for this overprediction will be examined later. A result of this sulfate overprediction is the $p \mathrm{H}$ underprediction observed above.

The aqueous-phase concentration of nitric acid remains much smaller than the ammonia and sulfate concentrations throughout the simulation until the fog dissipation stage. The maximum predicted concentration (excluding the fog dissipation) of nitric acid is $270 \mu \mathrm{eq} / \mathrm{L}$ versus the maximum observed value $240 \mu \mathrm{eq} / \mathrm{L}$. The model results indicate a larger variation in the nitrate concentrations than observed, and generally the observed values are somewhat higher than predicted. Possible explanations include the use of an incorrect initial gas and nitrate aerosol concentration profile, or an underprediction of the gas-phase nitric acid production rate.

The predicted and observed gas-phase concentrations of $\mathrm{SO}_{\underline{2}}$ at ground level are shown in Figure 9. The model predictions once more match adequately the observed val-
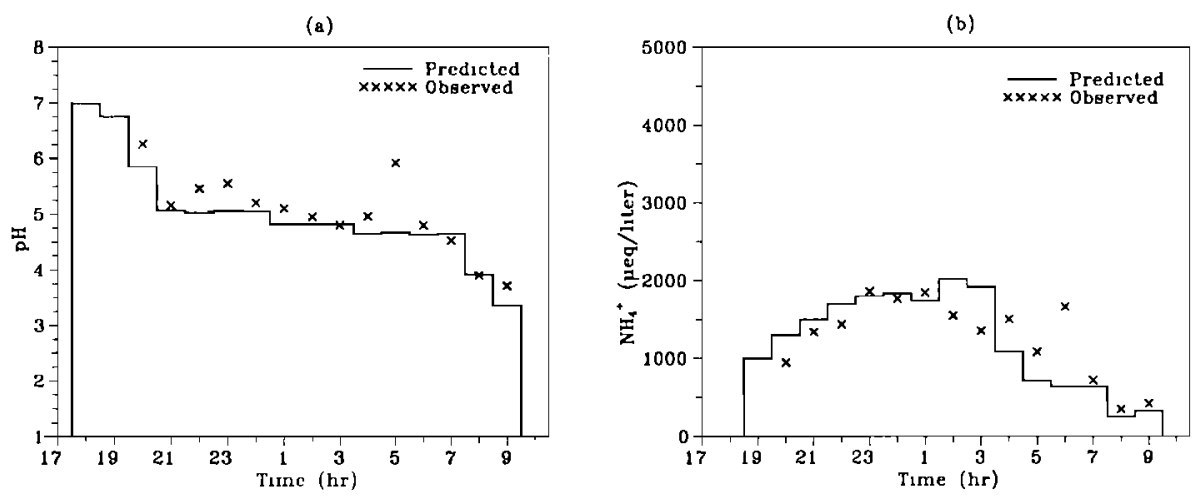

(c)
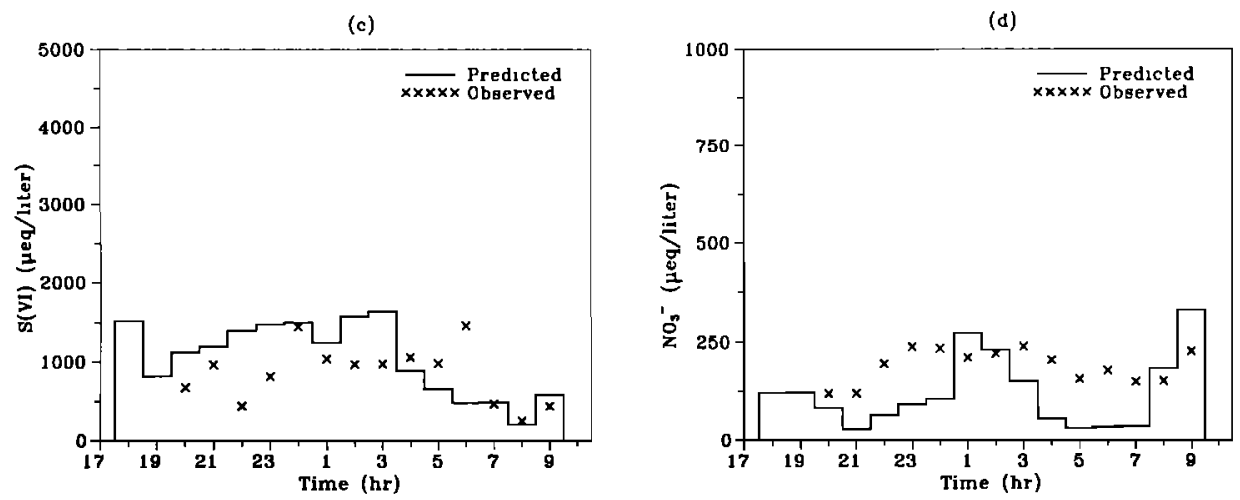

Fig. 8. Comparison of the predicted hourly averaged $(a) p \mathrm{H}$ values, $(b) \mathrm{NH}_{4}^{+},(c) \mathrm{S}(\mathrm{VI})$, and $(d) \mathrm{NO}_{3}^{-}$concentration for the ground-level grid cell with the observations of Waldman [1986]. 


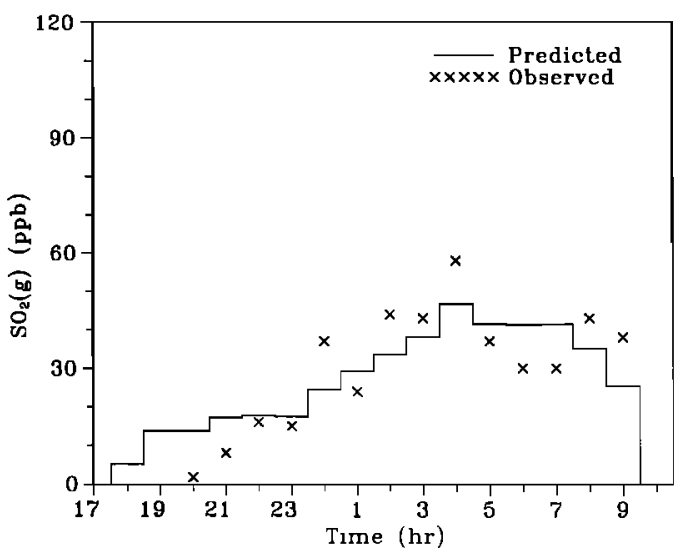

Fig. 9. Comparison of the predicted hourly averaged $\mathrm{SO}_{2}(\mathrm{~g})$ concentration for the ground-level grid cell with the observations of Waldman [1986].

ues. An average concentration of $40 \mathrm{ppb}$ is maintained during the night.

The behavior of the gas-phase concentrations of $\mathrm{HNO}_{3}$, $\mathrm{NH}_{3}$, and $\mathrm{H}_{2} \mathrm{O}_{2}$ is quite interesting (Figure 10). At 2300 the fog has reached a height of $140 \mathrm{~m}$. When the aqueous phase is not present in a cell, these three species exist in the gas phase. When the fog enters a cell, these species rapidly disappear either because of their high solubility in the aqueous phase $\left(\mathrm{NH}_{3}\right.$ and $\left.\mathrm{HNO}_{3}\right)$ or because of fast reactions in the aqueous phase $\left(\mathrm{H}_{2} \mathrm{O}_{2}\right)$. In this respect, the gravitational settling of the fog results in a "cleaning" of the lower atmosphere of these three species. The above model predictions agree with the reported gas phase concentrations of $\mathrm{HNO}_{3}$ and $\mathrm{NH}_{3}$ [Waldman, 1986] and the mutual exclusivity of $\mathrm{SO}_{2}$ and $\mathrm{H}_{2} \mathrm{O}_{2}$ in clouds reported by Kelly et al. [1985].

\section{Effect of Fog Development}

The influence of fog development on the dry aerosol mass concentration in the modeling region can be examined (Figure 11). The concentrations of sulfate, nitrate, and ammonium before fog development are the observed values that have already been used as initial conditions. To estimate

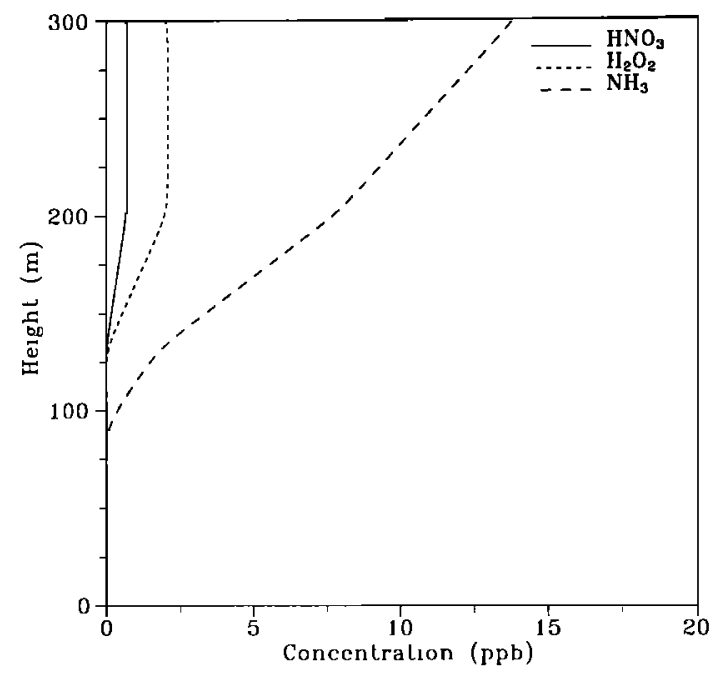

Fig. 10. Predicted $\mathrm{HNO}_{3}, \mathrm{H}_{2} \mathrm{O}_{2}$, and $\mathrm{NH}_{3}$ vertical gas-phase concentration profiles for 2300 PST.

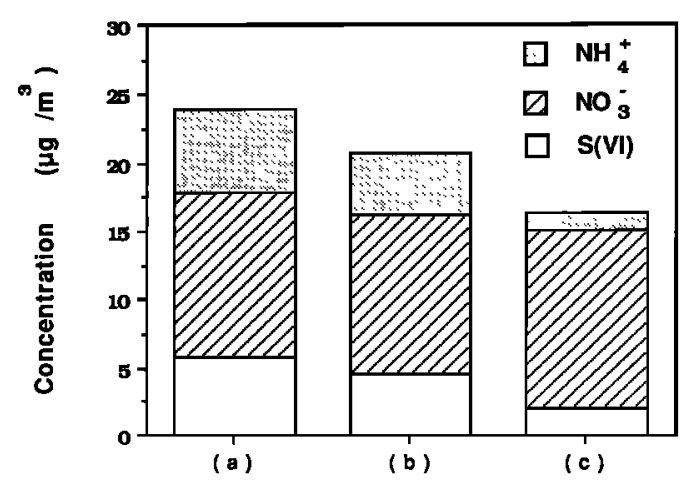

Fig. 11. Concentrations of the principal ionic species in the aerosol phase (a) vertically averaged concentration before fog formation (observed values used as initial conditions in the simulation), (b) predicted vertically averaged concentration after fog dissipation, $(c)$ predicted concentration for the ground-level grid cell after fog dissipation.

the corresponding concentrations after fog dissipation, we use the concentrations of these species at 0845 . The average concentrations refer to the entire modeling region $(1000 \mathrm{~m})$. A large part of this region has not been influenced substantially by the fog that occupied the lower $250 \mathrm{~m}$ only.

The predicted aqueous-phase concentrations for sulfate and ammonium suggest that for the case studied here, the corresponding aerosol concentrations will be reduced, especially near the ground. The nitrate concentration remains practically unchanged. The reasons for this behavior lie in the sinks and sources of these species under foggy conditions. The only source of ammonia is the ground-level emissions. The fog accelerates significantly the deposition of ammonia, resulting in a significant decrease of the ammonium concentration in the aerosol phase. The decrease of the sulfate concentration is found to be less than that of ammonium due to the production of sulfate in the aqueous phase. The relatively small change in the nitrate concentrations is due to the production of nitric acid in the gas phase during the last hour of fog life. This production is much faster near the ground, where the $\mathrm{NO}_{2}$ concentrations are higher in the early morning. This $\mathrm{HNO}_{3}(\mathrm{~g})$ is dissolved rapidly in the still existing aqueous-phase, resulting in a higher nitrate concentration.

An additional important question that should be addressed in the future concerns the effects of fog formation on the number concentration of aerosol particles as well as their size distribution. The present model can only predict aerosol mass, and a rigorous description of the aerosol particle microphysics must be added to address the above question.

\section{Wet Deposition Rates}

The average predicted and observed wet deposition rates for the major ionic species are presented in Figure 12. The observed values are measured at the ground level. The model tends to overpredict the deposition of all three species. The main reason for this is probably our assumption that the fog deposition velocity depends linearly on the liquid water content. Waldman [1986] reports that during this episode the liquid water variations appeared to be principally a function of droplet number concentration and the mass 


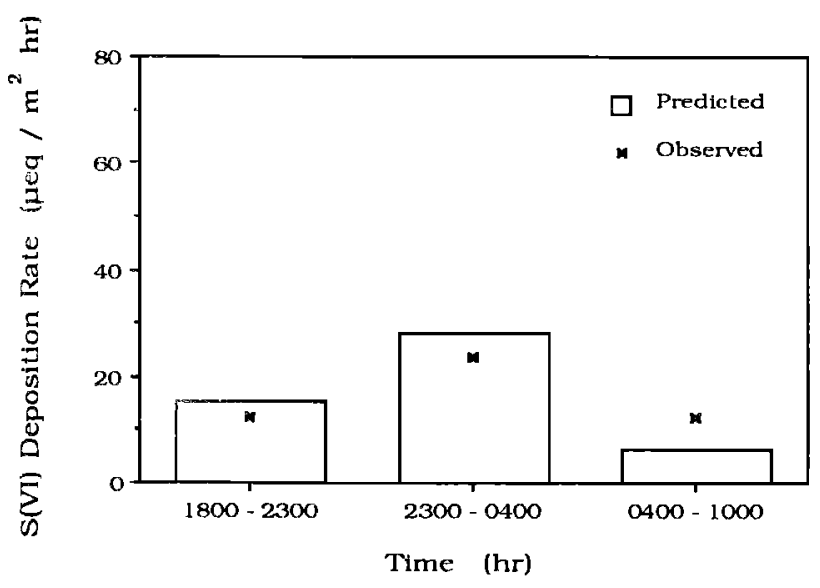

(a)

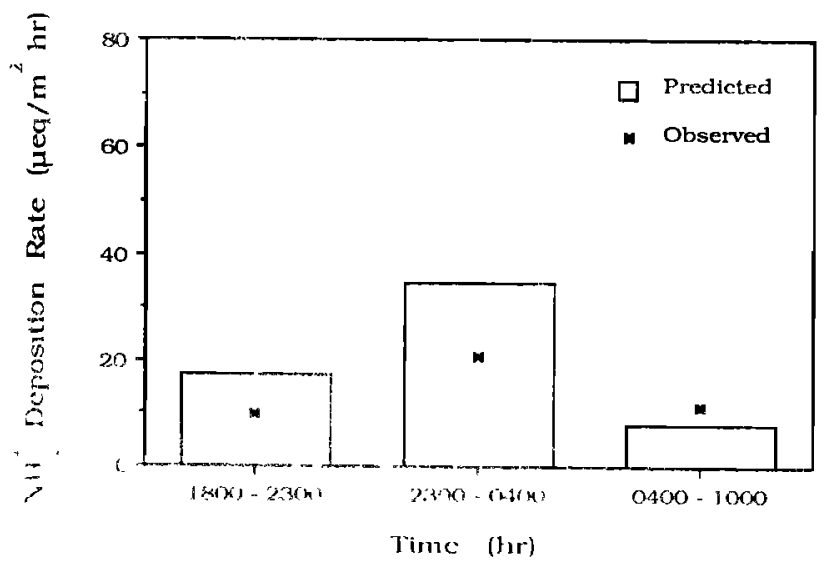

(b)

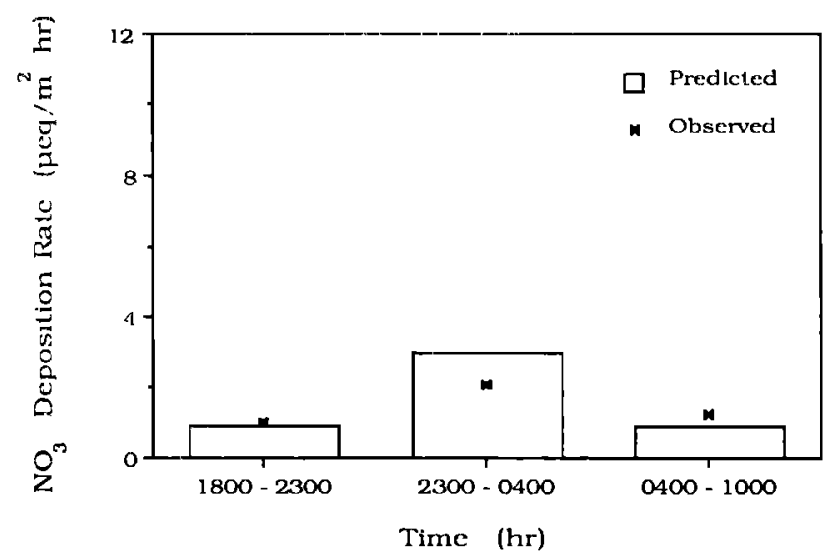

(c)

Fig. 12. Comparison of the predicted average wet deposition rates over three time periods with the observations of Waldman [1986] for (a) S(VI), (b) $\mathrm{NH}_{4}^{+}$, and (c) $\mathrm{NO}_{3}^{-}$.

median diameters remained in a relative narrow range. Therefore we have probably overpredicted the fog deposition velocity especially for the high liquid water values.

During the fog dissipation stage (0400-1000), the deposition rates are underpredicted because of the underprediction at this time of the corresponding aqueous-phase concentra-

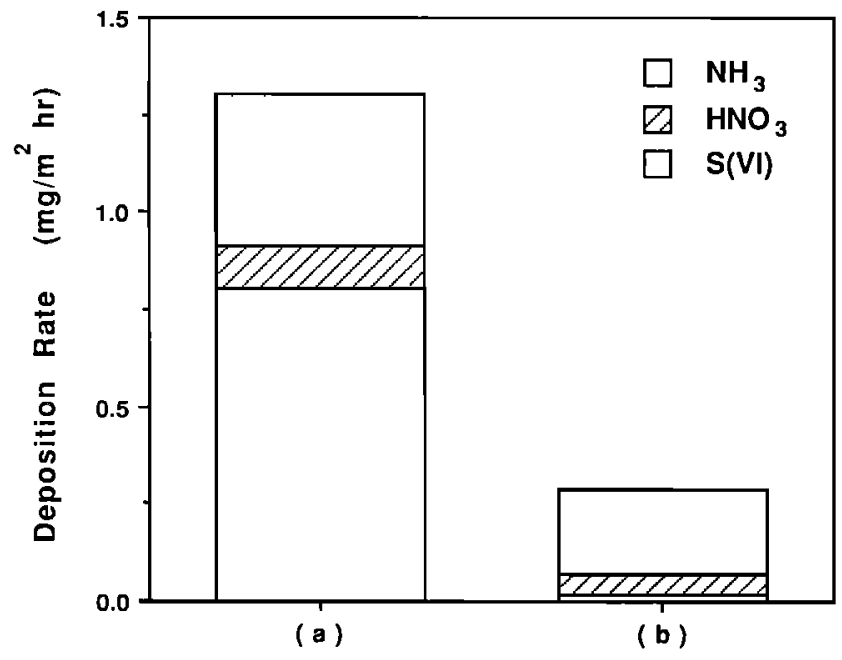

Fig 13. Comparison of the predicted average deposition rates for the same 16-hour period in $(a)$ presence of radiation fog, and $(b)$ absence of radiation fog.

tions (Figures $8 b-8 d$ ). The observed values of ammonia deposition rates are, according to Waldman, a lower bound due to ammonia losses, so disparity between the model and the actual values is less than appears in Figure $12 b$.

An interesting question that can be addressed is the effect of fog formation on total deposition rales. We have performed an additional simulation for the imaginary scenario that no fog was formed during the night of January 4-5. During this scenario, the only mechanism for deposition is the dry deposition of gases and aerosol. The calculation was performed according to the model described by McRae et al. [1982]. Due to the various simplifications used, the dry deposition rates are only reasonable estimates.

The results of this simulation are presented as the average deposition rates for the 16-hour period from 1800 January 4 to 1000 January 5 (Figure 13). These calculations suggest that because of fog formation, the total average deposition rate increased almost 3 times. The deposition of $S(I V)$ is found to increase only $25 \%$ because the gas-phase concentration decreases during the fog period. The most interesting change is the deposition of sulfate that increases about 30 times because of the sulfate production in fogwater. Ammonia and nitric acid gas-phase concentrations are very low inside the fog, so the corresponding dry deposition rates are very small, and the net increase is only twofold.

\section{Sulfate Production}

The main chemical change taking place in fogwater is the oxidation of S(IV) to S(VI) [Pandis and Seinfeld, 1989]. A mass balance for sulfur is presented in Figure 14 including the deposited masses of $\mathrm{S}(\mathrm{IV})(\mathrm{aq}), \mathrm{SO}_{2}(\mathrm{~g})$, and $\mathrm{S}(\mathrm{VI})$. The mass of sulfur existing as $S(I V)(a q)$ has not been included in the figure because it is much smaller than the rest of the entries.

During this fog episode, the main pathways for the production of sulfate are the oxidation of S(IV) by $\mathrm{H}_{2} \mathrm{O}_{2}, \mathrm{O}_{2}$ (catalyzed by $\mathrm{Fe}^{3+}$ and $\mathrm{Mn}^{2+}$ ), $\mathrm{HSO}_{5}^{-}$, and $\mathrm{NO}_{2}$ (Figure 15). Hydrogen peroxide oxidizes S(IV) rapidly but is also depleted rapidly because of the excess of $\mathrm{SO}_{2}(\mathrm{~g})$ in cases like the present one. One would expect that under these condi- 


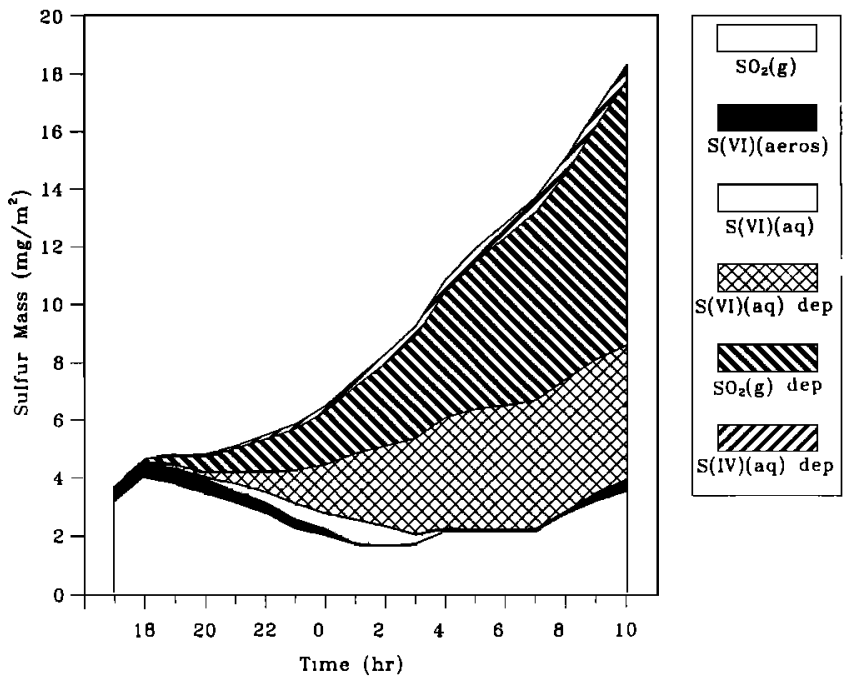

Fig. 14. Predicted sulfur mass balance for the lower $250 \mathrm{~m}$ of the atmosphere.

tions the contribution of hydrogen peroxide to the $\mathrm{SO}_{2}$ oxidation would be negligible shortly after the fog develops. This is, however, not the case. Due to the very stable conditions during the radiation fog life, hydrogen peroxide continues to exist in significant concentrations above the fog (Figure 10). As the fog continues to grow, new hydrogen peroxide is entrained into the fog and is available to oxidize S(IV). This process continues for almost 8 hours after the beginning of fog development, until 0200 . After this time, the contribution of hydrogen peroxide to S(IV) oxidation is indeed zero.

Due to the ammonia that gets continuously dissolved in the aqueous phase the $p \mathrm{H}$ of the fog is always greater than 4 except during the last 2 hours of fog life. Under these conditions the $\mathrm{Fe}^{3+}$ and $\mathrm{Mn}^{2+}$-catalyzed oxidation of $\mathrm{S}(\mathrm{IV})$ is predicted to be a major contributor to sulfate formation. After hydrogen peroxide is depleted from the fog region, this reaction becomes the major pathway for the $S(I V)$ to $S(V I)$ transformation.

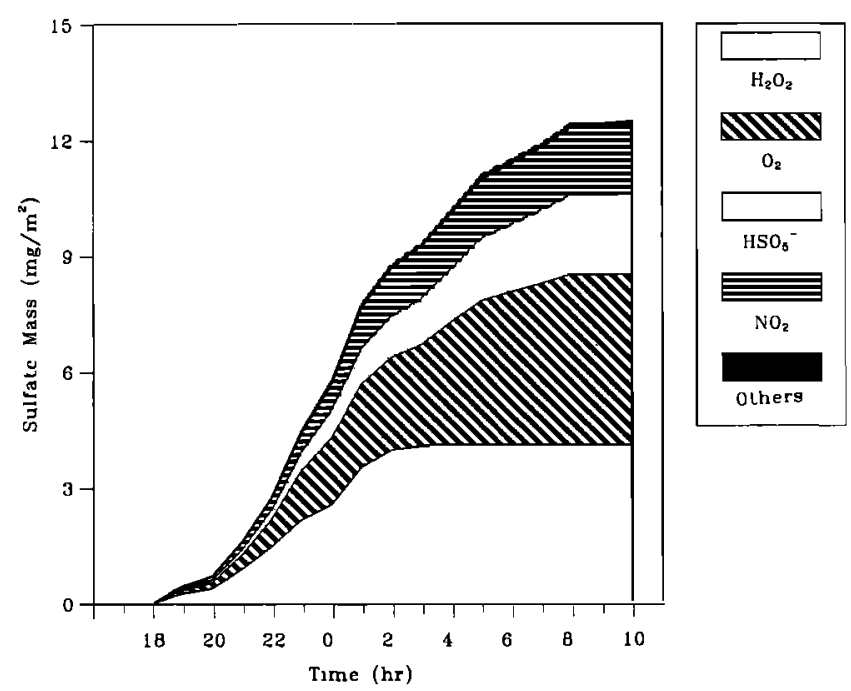

Fig. 15. Pathways for the production of sulfate during the radiation fog episode.
The gas-phase concentration of ozone during the night remains close to zero, and therefore the oxidation of S(IV) by ozone in the aqueous-phase is negligible. When ozone concentrations start to increase (around 0800), the fog has already begun to dissipate, and the fog $p \mathrm{H}$ is lower than 4, resulting again in negligible S(IV) oxidation by ozone.

An important pathway for sulfate production during this fog episode is the oxidation of S(IV) by $\mathrm{HSO}_{5}^{-}$:

$$
\mathrm{HSO}_{5}^{-}+\mathrm{HSO}_{3}^{-} \stackrel{\mathrm{H}^{+}}{\rightarrow} 2 \mathrm{HSO}_{4}^{-}+3 \mathrm{H}^{+}
$$

$\mathrm{HSO}_{5}^{-}$is one of the products appearing in the oxidation chain initiated by the attack of $\mathrm{OH}(\mathrm{aq})$ to $\mathrm{S}$ (IV) and propagated by further reactions of the radicals $\mathrm{SO}_{4}^{-}, \mathrm{SO}_{5}^{-}$, and $\mathrm{HSO}_{5}^{-}$[Jacob, 1986; Pandis and Seinfeld, 1989].

$A$ reaction that under the present conditions is found to contribute considerably to the sulfate production is that of $\mathrm{S}(\mathrm{IV})$ with $\mathrm{NO}_{2}$ :

$$
2 \mathrm{NO}_{2}+\mathrm{HSO}_{3}^{-} \stackrel{\mathrm{H}_{2} \mathrm{O}}{\longrightarrow} \mathrm{SO}_{4}^{2-}+3 \mathrm{H}^{+}+2 \mathrm{NO}_{2}^{-}
$$

This reaction has been studied by Lee and Schwartz [1983] at

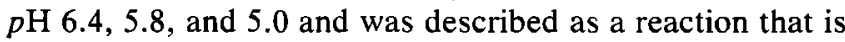
first order in $\mathrm{NO}_{2}$ and first order in S(IV), with a $p \mathrm{H}$ dependent rate constant. The evaluation of this rate expression was considered tentative by Lee and Schwartz, in view of evidence for the formation of a long-lived intermediate species. The apparent rate constant was found to increase with increasing $p \mathrm{H}$. This reaction was considered of secondary importance at the concentrations and $p \mathrm{H}$ values representative of clouds. Under the conditions of the radiation fog in the San Joaquin Valley, the importance of this reaction increases considerably over that in clouds. The major reason is that the emitted $\mathrm{NH}_{3}$ is scavenged by the fog droplets, maintaining a low fogwater acidity. Therefore this reaction is not self limiting in fog to the extent that it is in clouds. Other reasons for the significance of this reaction for this case are the relatively high gas-phase concentrations of $\mathrm{SO}_{2}$ and $\mathrm{NO}_{2}$. Radiation fogs develop under stable meteorological conditions, and in polluted environments they occur at the same altitude as the sources of $\mathrm{SO}_{2}$ and $\mathrm{NO}_{x}$. Consequently, the gas phase concentrations of $\mathrm{SO}_{2}$ and $\mathrm{NO}_{2}$ can be much higher in a fog than inside a cloud, and the aqueous-phase reaction of $\mathrm{S}(\mathrm{IV})$ with $\mathrm{NO}_{2}$ can be much faster.

Due to the remaining questions concerning the kinetics of this reaction, our results should be considered tentative. The fact that the model overpredicts the sulfate concentrations could be the result of a high initial $\mathrm{H}_{2} \mathrm{O}_{2}$ concentration, an overprediction of the oxidation of $\mathrm{S}(\mathrm{IV})$ by $\mathrm{NO}_{2}$, or an overprediction of the $\mathrm{S}(\mathrm{IV})$ oxidation rate by $\mathrm{O}_{2}$ (catalyzed by $\mathrm{Fe}^{3+}$ and $\mathrm{Mn}^{2+}$ ).

\section{Sensitivity to Deposition}

The sensitivity of the model to the expression of the mean settling velocity, $u_{a v}$, as a function of the liquid water content has been investigated by performing an additional simulation using the value $a_{\mathrm{g}}=0.06$ (case II) instead of $a_{\mathrm{g}}=$ 0.12 used for the base case (case I). Therefore for the same liquid water content, the settling velocity in case II is half the settling velocity of case $I$. This reduction in settling velocity 
accelerates the fog growth by $10-20 \mathrm{~m}$ and increases the liquid water content of the fog by almost $30 \%$. The mature

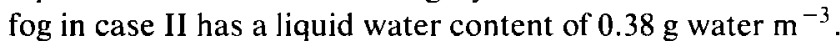
The rate of liquid water mass deposited to the ground in case II is only around $10 \%$ less than that in case I. This is due to the fact that the decrease of the water deposition rate because of the smaller value of the parameter $a_{\mathrm{g}}$ is partially balanced by the increase of the liquid water content.

The aqueous-phase concentrations of the main ionic species, $\mathrm{S}(\mathrm{VI}), \mathrm{NH}_{4}^{+}$, and $\mathrm{NO}_{3}^{-}$in case II are initially (at 2000 PST) around $25 \%$ lower than the corresponding concentrations in case I because the increase of the liquid water causes a higher dilution. Therefore case I is characterized initially by higher ionic concentrations and higher water deposition rates than case $I I$, or equivalently by higher initial ionic deposition rates. This difference in the deposition rates of the major ions causes a convergence of the calculated ionic concentrations, and after 0400 PST the calculated concentration difference is less than $5 \%$. At the same time the total mass of the ionic species dissolved in the aqueous phase is for case II as much as $30 \%$ larger compared with case I due to the higher liquid water content.

Summarizing, a 50\% decrease in the parameter $a_{\mathrm{g}}$ causes an average increase of the fog liquid water content by $30 \%$, an average decrease of the liquid water deposition rate by $10 \%$, an initial decrease of $25 \%$ in the aqueous-phase concentrations of the major ions that finally reduces to less than $5 \%$, and an increase of the total mass of the major ions in the aqueous phase by as much as $30 \%$. These results indicate that a good estimate of $a_{\mathrm{g}}$ is required by the model and, furthermore, that the gravitational settling of fog droplets affects considerably the chemical composition of fogwater.

An additional test has been performed to study the importance of the deposition process in acidic deposition. In an imaginary scenario the water droplet settling has been neglected, and the liquid water content has been assigned a constant value of $0.3 \mathrm{~g} \mathrm{~m}^{-3}$, conditions that can be generally applied to a cloud simulation (case III). Only one computational cell has been used for this simulation, and the rest of the conditions (initial gas and aerosol concentrations, emissions, etc.) are the same as in the base case (case I). The fact that all the liquid water remains in the modeling region results in much higher concentrations of the major ionic species. The average $\mathrm{S}(\mathrm{VI}), \mathrm{NH}_{4}^{+}$, and $\mathrm{NO}_{3}^{-}$are $2.5,3$, and 2.7 times larger in case III than in the base case. The $p \mathrm{H}$ in case III remains higher than in the base case until the fog dissipation stage, when the $p \mathrm{H}$ is practically the same for both cases. The higher $p \mathrm{H}$ in case III can be explained by the fact that the neutralizing agent, ammonia, is not depleted from the system, keeping the $p \mathrm{H}$ at higher values. The gradual increase in the sulfate and nitrate concentrations finally compensates for this higher ammonia concentration, and the $p \mathrm{H}$ difference for the two cases becomes essentially zero after 0600 PST.

\section{ConClusions}

The physical and chemical processes leading to acidic deposition during a radiation fog episode have been studied using a one-dimensional mathematical model. The model used in this study combines a detailed description of gaseous and aqueous chemistry with a dynamic model describing radiation fog development. Variables predicted by the model include the vertical profiles of temperature, relative humidity, and liquid water content, the vertical concentration profiles of species in the gaseous and aqueous phase, and the wet deposition rates for all species.

Application of the model to a radiation fog episode in Bakersfield in the San Joaquin Valley of California over the period January $4-5,1985$, shows that the model predictions for temperature profile, fog development, liquid water content, gas-phase concentrations of $\mathrm{SO}_{2}, \mathrm{HNO}_{3}$, and $\mathrm{NH}_{3}$, $p \mathrm{H}$, aqueous-phase concentrations of $\mathrm{SO}_{4}^{2-}, \mathrm{NH}_{4}^{+}$, and $\mathrm{NO}_{3}^{-}$, and finally deposition rates of the above ions match well the observed values.

The formation of the specific radiation fog causes reduction of the aerosol $\mathrm{NH}_{4}^{+}$and $\mathrm{SO}_{4}^{2-}$ content. The $\mathrm{NO}_{3}^{-}$ content remains practically the same as that predicted in the absence of a fog due to production of nitric acid in the gas phase during the last 3 hours of fog life and subsequent dissolution of $\mathrm{HNO}_{3}$ in the existing aqueous phase. The deposition rates of the major ions are found to increase drastically during the fog episode, with increase of sulfate deposition being the most notable.

Several differences exist between a radiation fog and a representative cloud environment. Radiation fog develops typically under stable conditions, resulting in weak mixing and significant gradients in the vertical profiles of species like hydrogen peroxide, ammonia, and nitric acid. The deposition process during a dense radiation fog leads to rapid removal from the atmosphere of the major ionic species and tends to keep their corresponding fogwater concentrations to lower values. Because of the proximity of the fog to groundlevel sources of pollutants like $\mathrm{SO}_{2}$ and $\mathrm{NO}_{r}$, the corresponding gas-phase concentrations can reach much higher levels than in a cloud. In such a case, pathways for the sulfate production that are of secondary importance in a cloud environment may become significant in a fog.

Expressing the mean droplet settling velocity as a function of liquid water content is found to be influential in the prediction of fog liquid water content, the total masses of the major ionic species in the aqueous phase, and the concentrations of these species in the first half of the fog life.

In the present model, aerosol or fog droplet size dependent processes such as aerosol nucleation, condensation, and coagulation, droplet growth, evaporation, and settling have either been described in terms of overall properties of the fog or have been omitted. The next level of detail in the modeling of acid deposition due to fog episodes requires the coupling of this model with one describing aerosol and fog droplet microphysics.

Acknowledgments. We would like to thank W. G. Zdunkowski and A. Bott, Institut fur Meteorologie, Johannes Gutenberg Universitat, Mainz, for providing us with the code for the radiation scheme and for helpful comments. We would like also to thank W. P. L. Carter, University of California, Riverside, for providing us with his software for the gas-phase mechanism preparation and emissions processing. This work was supported by the State of California Air Resources Board under agreement A732-043.

\section{REFERENCES}

Aerovironment Inc., AVKERN application report, Rep. $A V$ FR-83/501R2, Pasadena, Calif., 1984

Brown, R., A numerical study of radiation fog with an explicit formulation of the microphysics, Q.J.R. Meteorol. Soc., 106, 781-802, 1980. 
Brown, R., and W. T. Roach, The physics of radiation fog, II, A numerical study, Q. J. R. Meteorol. Soc., 102, 335-354, 1976.

Carter, W. P. L., and R. Atkinson, Development and implementation of an up-to-date photochemical mechanism for use in airshed modeling, summary final report, Calif. Air Resour. Board, Sacramento, 1988.

Carter, W. P. L., F. W. Lurmann, R. Atkinson, and A. C. Lloyd, Development and testing of a surrogate species chemical reaction mechanism, Rep. EPA-600/3-86-031, Environ. Prot. Agency, Washington, D. C., 1986.

Chameides, W. L., The photochemistry of a marine stratiform cloud, J. Geophys. Res., 89, 4739-4755, 1984.

Eagleman, J. R., Meteorology, The Atmosphere in Action, Wadsworth Publishing, Belmont, Calif., 1985.

Fisher, E. L., and P. Caplan, An experiment in the numerical prediction of fog and stratus, J. Atmos. Sci., 20, 425-437, 1963.

Forkel, R., W.-G. Panhans, R. Welch, and W. Zdunkowski, A one-dimensional numerical study to simulate the influence of soil moisture, pollution and vertical exchange on the evolution of radiation fog, Beitr. Phys. Atmos., 57, 72-91, 1984.

Forkel, R., U. Sievers, and W. Zdunkowski, Fog modelling with a new treatment of the chemical equilibrium condition, Beitr. Phys. Atmos., 60, 340-360, 1987.

Graedel, T. E., and K. I. Goldberg, Kinetic studies of raindrop chemistry, 1, Inorganic and organic processes, J. Geophys. Res., 88, 10,865-10,882, 1983.

Heikes, B. G., G. L. Kok, J. G. Walega, and A. L. Lazrus, $\mathrm{H}_{2} \mathrm{O}_{2}$, $\mathrm{O}_{3}$, and $\mathrm{SO}_{2}$ measurements in the lower troposphere over the eastern United States during the fall, J. Geophys. Res., 92, 915-931, 1987.

Jacob, D. J., The origins of inorganic acidity in fogs, Ph.D. thesis, Calif. Inst. of Technol., Pasadena, 1985.

Jacob, D. J., Chemistry of OH in remote clouds and its role in the production of formic acid and peroxymonosulfonate, J. Geophys. Res., 91, 9807-9826, 1986.

Jacob, D. J., and M. R. Hoffmann, A dynamic model for the production of $\mathrm{H}^{+}, \mathrm{NO}_{3}$, and $\mathrm{SO}_{4}^{2-}$ in urban fog, J. Geophys. Res., 88, 6611-6621, 1983.

Jacob, D. J., J. M. Waldman, J. W. Munger, and M. R. Hoffmann, Chemical composition of fogwater collected along the California Coast, Environ. Sci. Technol., 19, 730-736, 1985.

Jacob, D. J., F. H. Shair, J. M. Waldman, J. W. Munger, and M. R. Hoffmann, Transport and oxidation of $\mathrm{SO}_{2}$ in a stagnant foggy valley, Atmos. Environ., 21, 1305-1314, 1987.

Kelly, T. G., P. H. Daum, and S. E. Scwartz, Measurements of peroxides in cloudwater and rain, J. Geophys. Res., 90, 7861$7871,1985$.

Lala, G. G., E. Mandel, and J. E. Jiusto, A numerical evaluation of radiation fog variables, J. Atmos. Sci., 32, 720-728, 1975.

Lee, Y.-N., and S. E. Schwartz, Kinetics of oxidation of aqueous sulfur(IV) by nitrogen dioxide, in Precipitation Scavenging, Dry Deposition, and Resuspension, vol. 1, edited by H. R. Pruppacher, R. G. Semonin, and W. G. N. Slinn, Elsevier, New York, 1983.

McDonald, J. E., The saturation adjustment in numerical modelling of fog, J. Atmos. Sci., 20, 476-478, 1963.

McRae, G. J., W. R. Goodin, and J. H. Seinfeld, Development of a second generation mathematical model for urban air pollution, I, Model formulation, Atmos. Environ., 16, 679-696, 1982.

Munger, J. W., D. J. Jacob, J. M. Waldman, M. R. Hoffmann, Fogwater chemistry in an urban atmosphere, J. Geophys. Res., $88,5109-5121,1983$.

Munger, J. W., J. Collett, B. Daube, and M. R. Hoffmann, Fogwater chemistry at Riverside, California, Atmos. Environ., in press, 1989.

Pandis, S. N., and J. H. Seinfeld, Sensitivity analysis of a chemical mechanism for aqueous-phase atmospheric chemistry, J. Geophys. Res., 94, 1105-1126, 1989.

Pruppacher, H. R., and J. D. Klett, Microphysics of Clouds and Precipitation, D. Reidel, Hingham, Mass., 1980.

Schwartz, S. E., Gas- and aqueous-phase chemistry of $\mathrm{HO}_{2}$ in liquid water clouds, J. Geophys. Res., 89, 11,589-11,598, 1984.

Seigneur, C., and P. Saxena, A study of atmospheric acid formation in different environments, Atmos. Environ., 18, 2109-2124, 1984.

Seigneur, C., and P. Saxena, A theoretical investigation of sulfate formation in clouds, Atmos. Environ., 22, 101-115, 1988.

Shir, C. C., A preliminary numerical study of atmospheric turbulent flows in the idealised planetary boundary layer, J. Atmos. Sci., 30, 1327-1339, 1973.

Ten Brink, H. M., S. E. Schwartz, and P. H. Daum, Efficient scavenging of aerosol sulfate by liquid water clouds, Atmos. Environ., 21(9), 2035-2052, 1987.

Tremblay, A., and $H$. Leighton, The influence of cloud dynamics upon the redistribution and transformation of atmospheric $\mathrm{SO}_{2}$ A numerical simulation, Atmos. Environ., 18, 1885-1894, 1984.

Tremblay, A., and H. Leighton, A three-dimensional cloud chemistry model, J. Clim. Appl. Meteorol., 25, 652-671, 1986.

Turton, J. D., and R. Brown, A comparison of a numerical method of radiation fog with detailed observations, $Q . J . R$. Meteorol. Soc., 113, 37-54, 1987.

U.S. Environmental Protection Agency, Development of the 1980 NAPAP emissions inventory, Rep. EPA/600/7-86/057a, Washington, D. C., 1986.

Walcek, C. J., and G. R. Taylor, A theoretical method for computing vertical distributions of acidity and sulfate production within cumulus clouds, J. Atmos. Sci., 43, 339-355, 1986.

Waldman, J. M., Depositional aspects of pollutant behavior in fog, Ph.D. thesis, Calif. Inst. of Technol., Pasadena, 1986.

Waldman, J. M., J. W. Munger, D. J. Jacob, R. C. Flagan, J. J. Morgan, and M. R. Hoffmann, Chemical composition of acid fog, Science, $218,677-680,1982$

Zdunkowski, W. G., and B. C. Nielsen, A preliminary prediction analysis of radiation fog, Pure Appl. Geophys., 75, 278-299, 1969.

Zdunkowski, W. G., R. M. Welch, and J. Paegle, One-dimensional numerical simulation of the effects of air pollution on the planetary boundary layer, J. Atmos. Sci., 33, 2399-2414, 1976.

Zdunkowski, W. G., W.-G. Panhans, R. M. Welch, and G. J. Korb, A radiation scheme for circulation and climate models, Beitr. Phys. Atmos., 55, 215-238, 1982.

S. N. Pandis and J. H. Seinfeld, Department of Chemical Engineering and Environmental Quality Laboratory, California Institute of Technology, Pasadena, CA 91225.

(Received February 2, 1989; revised June 12, 1989; accepted June 12, 1989.) 